Student Success

ISSN: 2205-0795

Volume 9, Issue 1, pp. 1-7

February 2018

\title{
Feature
}

\section{Enabling Future Directions: NAEEA Invited Panel}

\author{
Thomas Roche and Suzi Syme
}

Southern Cross University, Lismore, Australia

\section{Abstract}

To bookend the 6th Biennial National Association of Enabling Educators of Australia (NAEEA) Conference, five invited speakers joined a panel on the future directions of enabling education locally and globally: David Bull, founding and outgoing Chair of the Association and also the Director of the University of Southern Queensland's Open Access College, Australia; Professor Mike Osborne, Director of the Centre for Research and Chair of Adult and Lifelong Learning (CR\&DALL) at the University of Glasgow, United Kingdom; Professor Karen Nelson Pro Vice-Chancellor (Students) at the University of the Sunshine Coast, Australia; Professor Norm Sheehan, a Wiradjuri man and Director of Gnibi College at Southern Cross University, Australia; Associate Professor Nick Zepke Massey University, New Zealand. The panel discussion was facilitated by Karen Seary, Associate Dean at CQUniversity and recently elected Chair of the NAEEA. The panellists encouraged NAEEA members to strengthen enabling practice through a robust approach to research and documenting their practice whilst focusing on students and their success. The following excerpts were taken from a transcription of the panel by the authors, who have made all attempts to ensure the accuracy of information presented.

Please cite this article as:

Roche, T., \& Syme, S. (2018). Enabling Future Directions: NAEEA Invited Panel. Student Success, 9(1), 1-7. doi: 10.5204/ssj.v9i1.428

Student Success: A journal exploring the experiences of students in tertiary education

(c) (i) This work is licensed under a Creative Commons Attribution 4.0 International Licence. As an open access journal, articles are free to use, with proper attribution, in educational and other non-commercial settings. ISSN: 2205-0795 


\section{Strong demand but challenges ahead}

David Bull: I want to start with something really positive. I think that the demand for enabling education is going to continue to grow. It's so strong, and I think that we're not going to see any relapse in that strength. At the current time there's something like, 9,680 enabling places funded by the government in Australia. I don't see that changing.

However, one thing that I think we should all be very aware of as a result of the last 12 months is that we cannot blissfully operate without being extremely conscious of the political environment in which we're operating. The last 12 months have thrown up a lot of threats to the provision of enabling education, that we haven't seen arise before, but perhaps we should have been aware that they would come up, sooner or later. We've had two decades of pretty smooth sailing with enabling provision, which provided fee free places, up to a certain number. And up to this point in time it's never really been challenged before. But as you're all aware the HESLA (Higher Education Support Legislation Amendment) legislation that was proposed earlier this year really could have potentially decimated enabling education as we know it.

The first aspect of it was the proposal to introduce student fees that students would be asked to contribute if they were going to be participating in enabling programmes. I am of the opinion that would make a significant impact upon the students who currently enrol in our enabling programmes. And that very many of them would be deterred from enrolling in the first place.

The second threat as I see it, is this business about performance indicators. Now if enabling education gets the same sort of performance indicators that the Government is proposing, and if it's applied to enabling education the way it's being proposed to be applied to undergraduate programmes, we'd look bad. We have poor attrition rates. We can't be compared in the same way and expect to come up with performance figures that are comparable to standard undergraduate programmes.

The third thing I'm really concerned about is where these programmes might be located in the future. There are a number of documents which have argued quite strongly that enabling education programmes are best situated within universities. That we're able to give the students the sort of enculturation and experience that they would most benefit from. Better than say, even the TAFE sector, or private providers. However, as we know, governments are very much concerned about cost savings, and cost efficiencies, and private providers, for example, could probably provide some sort of enabling programmes for a lot less money than universities might be able to. I think we've got to be very aware of our political environment in which we operate, and as the Association moves forward I think we have to find ways to mitigate the sorts of proposals we may go up against legislatively.

It would particularly impact upon those that we have tried to target. Those that are the most disadvantaged and marginalised in our society. They would be the ones who would be the ones least likely to be able to participate if fees were introduced.

David Bull

\section{Provide evidence of adding value}

Nick Zepke: I've flown across the ditch from New Zealand and so all I can provide you, in this futures look, is a bird's eye view, from way above. Because I don't know enough about the details of the legislation, or the statistics. So, a general view.

\section{2 | Student Success, 9(1) February 2018}


The first point I would make is, Karen Nelson has produced for you a fantastic basis from which to plan forward. She's developed data from which to develop, she's got a model from which to work, and I would suggest that you would look at Karen's work more closely and start working on that.

The second point I would make is that the future essentially is unknowable,

My next point, is that political work is required. The Association can play a really important part in that political work, to persuade the politicians of the data you've got, and the energy you've got, and the program you've got, the success you've had. That they are valuable, important, in fact they are vital.

The next point obviously hinges around success, and I think part of the political work that's required is to open out the view of success that the politicians have. And not just to go with the hard outcomes like retention. But to also emphasise the value that you add with your programs to individuals' lives, and to the society that you live in.

The second to last point is that I have been really impressed by two things. The first thing is the research base that is being built within this Association. I recommend that you develop that research base, because politicians are impressed with data. I think to develop those is an important aspect of your prosperity, and to the future.

My last point is keep the enthusiasm. Keep the spirit. I have been to many, many conferences. But I have been to very few that has the same engagement as this one has, and if this is an example of the enthusiasm of your field, in education, then I think the future, if not actually rosy, will at least be secure. Thank you.

\section{In future work it will be important to have} the data, to have the information.

Nick Zepke

\section{Significance, originality and rigour}

Mike Osborne: I too have been very impressed by the commitment of many people towards doing research, and from my experience in the UK, access has been the agenda for many years. What's been missing to large extent is longitudinal research over a period. It would be very interesting, would it not, to see what happened to those children in 15 years' time, in terms of their participation in higher education, because of the participation of parents, or the other way around, depending on the initiative. The fact that the children are doing something different, does that affect the parents?

As Nick has said, having really, really good data to justify what you're doing is very important. I was also thinking of ways in which you collect data as well. There are many alternative ways of collecting data now. And for example, in the session I did on Wednesday I didn't get around to talking in great detail about the sort of work that we do using big data. And the approaches that can be used in learning analytics, the approaches that can be used using GPS tracking and so on. There's work in the US that shows the relationship between how students use campus facilities, and their grade point average. Which then can be used to make interventions. And it's said that GPA can predicted within plus or minus 0.1 on the basis of monitoring how students use facilities.

Now that's not to say that you can tell students to do this and that, but you could possibly say to students "Well look at your GPA, and look at what you're doing," and so on, and use that for 
interventions. And there are all sorts of apps, you know, I've looked at the literature on student engagement, there are student engagement apps that can be used to send reminders to students about various things that they're doing. All I'm really saying is that it doesn't have to be large scale surveys, it doesn't have to be even huge numbers of interviews. There are other approaches that you can make. But I would say, it's got to be robust.

And I'm afraid educational research in the social sciences tends to be at the bottom of the heap. Adult education research tends to be below

It's the significance, originality, and rigour - rigour over anything else is so important in research.

Mike Osborne

educational research, in the way in which people perceive it. But there's no need for that, you've got masses of data, and you can write really good stuff, that could be published in the very best journals, and that's going to have an impact. And that's got to be coupled, of course, again repeating, to an extent, what Nick's said, by coming out with sound-bites. Coming out with the really important stuff that's going to catch the attention of politicians.

The other thing, is about challenge. And if enabling education, or access as we would call it, is going to work, it's got to combine a highly supportive environment, with a challenging environment. We have got to challenge our students to do things that they think they can't do, but they can of course. If we support them in the right ways. We must expect a lot of our students, but at the same time support them.

\section{On building future societies}

Norm Sheehan: The future, that's quite an interesting thing. One of my favourite theorist in education is Basil Bernstein, in his works he said there's two levels in education. There's the informational discourse, and then there's the social positioning discourse. Analyse that. It tells people what their position is, in relation to that information. That sort of understanding opens up for our students, for Aboriginal students, the idea of, "Is there a possibility for them to see themselves in the studies they do in higher education?" Because essentially what's happening. Our students are learning another culture.

In our new degree, our introduction to Indigenous scholarship, the curriculum does two things. It shows our Indigenous students how to engage with the culture of the university, and it shows our non-Indigenous students how to engage with the culture in the school. That crossover is really quite a valuable crossover. When we look at the potential for that, probably the biggest potential in this university is around climate change, and sustainability. Because measurement doesn't work, evidence doesn't work. If you're moving in a direction, evidencebased practice is the driver sitting in the back of the vehicle, seeing what's being run over.

Universities are actually about building future societies. If you bring in the people from the margins, and from the bottom, which is what you are doing, you're not bringing in the ' $A$ ' class students from high schools, you're bringing in people who have missed out.

Norm Sheehan 
The thing is, for our future you actually need to change things in enabling education to actually change the framework.

I actually failed high school. I did a wonderfully elegant fail. At the 25 year anniversary reunion of my high school, I turned up there and I said "I've worked in a university," and they said, "Ha ha, as a gardener?" and I said "No actually, that guy over there who's a teacher, he's a student in the program that I'm coordinating." People couldn't believe it. I couldn't believe it either, because they actually found out through my doing an enabling program, being supported, that I had a brain, and I could properly use it. So, one of the things for the future is enabling social change, and bringing life to people. That is meaningful, and that is what higher education is about.

\section{Reaching out to the periphery}

Karen Nelson: I was really taken by what Norm's just said, and it reminds me of our colleague, Trevor Gale, who wrote in about 2012, about a southern theory of education. He didn't mean southern as about below the equator, he meant southern as in reaching out to the people who are on the periphery, and finding ways to include them in the culture, and the thinking, and the social structures of education.

That work is not complete is it? The work that we're all engaged in enabling, is part of that process. I'd like to think of a future where the secrets of success for students, that are embedded in the work that you all do in enabling programs, becomes the way we think about bringing students into the higher education system - it builds capacity in students.

The development of self, and as citizen, is profound, and we know through our own experience that the same concentrated impact doesn't always get through in the mainstream. I like to think about a future of enabling that is the way we actually go about transitioning students in, rather than the exception.

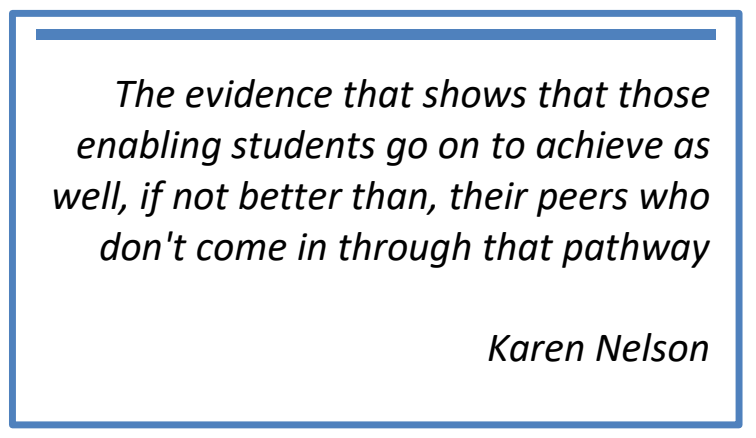

\section{The questions: outcomes, financial and beyond}

Audience Speaker 1: $\quad$ None of us would be here if we weren't committed to the idea that education and raising social capital had some intrinsic social value beyond itself. But the reality is, that with increasing levels of debt attached to attaining a degree, that for many of our students, particularly mature aged students, in regional and remote areas, getting a degree has intrinsic value, but doesn't necessarily translate into improved outcomes for them in health, in housing, or in income. Given the pressure we are on to transfer these students into undergraduate degrees, we are ethically, not infrequently, in something of a fix.

Mike Osborne: I've written about this on more than one occasion in relation to access to higher education in the UK. There is this quite a substantial literature and research around the financial benefits of life-long learning and what you're saying is absolutely correct: that depending on what period in life you enter into higher education, on whether you take a short cycle in higher education or a longer cycle one, depending on whether you're a man or woman, depending on the type of institution you go to, that there are very different benefits in terms of outcomes, when we talk about the financial benefits.

Whilst we talk, there are obviously wider benefits than financial benefits. But those two 
can't really be disentangled because most people are looking for some sort of improvement of their own personal life, and in that of their families. I think that we do have to be honest with students, and we do have to point them in what is the right direction for them. Doing a twoyear program that is in a highly vocational area, for many people, might be the right thing to do. We might want to create a greater flexibility for them so that we can think of work as being the first possible outcome after say two years. And create flexibility, which obviously we have in our systems.

David Bull: You can't expect a student to study if they're homeless or hungry. Sometimes the best advice is that they need to take a different path in the short term. Or as Mike has suggested, undertaking shorter term study that might give them a smaller step towards a better quality of life.

\section{A culture of care}

Norm Sheehan: It's an interesting thing, because if you look at Aboriginal academics and professionals in Australia, there's a whole different set of pressures that don't exist, and we don't say to our students "This is going to make it easier." We actually say, this is going to make it harder, but what it does do for us, is it eases the boundaries around what's possible for the next group of people to come through. It's a generational thing. It is not an easy path, and it's never presented that way from our point of view. It's actually a path where people need elders to mentor and support them all the way. And that care, that culture of care is part of our way of doing things.

It's part of the way that I think we can contribute to the wider community, by showing people how to show that care as part of an education process. The responsibility of a teacher and the care of an institution for the people they teach. And it's not just filling them up with something that they can take somewhere for their own benefit. It's actually developing relationships that sustain, and co sustain people. And that's the aim from my perspective. To develop those relationships that are strong, moral, effective, and loving, for our students.

Audience speaker 2: We need strategies that are about people's lives, not about departments of government. There's those other factors, the structural factors, and that the environment that are so influential. That unless we address some of those factors it's going to continue to be challenging for large proportions of our population to fully engage.

David Bull: I'm also thinking though, about changing the idea of success, and what the purpose of an education is. That it's not just to get a degree. Now that's a big statement. How do you achieve that? Well in small incremental steps, I suggest. I think that's a might avenue to pursue that would be really interesting, is if the whole sector got together and developed a whole data set and that then can be started to be given to politicians.

\section{What needs changing?}

Audience speaker 3: I wanted to ask you what you felt needed to change in enabling education in response to an ageing demographic in Australia.

David Bull: Perhaps we should be asking what needs to change in enabling education for a changing economy, and technology. Because I mean things are changing so rapidly in our space that the world of work is altering almost every day. And I mean there are quite big questions around whether universities, and university programs, as they stand are actually going to be serving the students they're currently educating and providing them with the real attributes in schools that they're actually going to require in 10 , or 15 or 20 years' time.

I'd like to kind of put it back that way. I think we need to think more about where the world is going, where the country is going in terms of the 
changes, societal and technological changes, and how we should be modifying our programs to meet that sort of future.

Norm Sheehan: The idea for us, for elders, is respecting history, collecting, having people tell their stories, which are very difficult stories to tell. And the benefit that has for all of our communities. Recording that knowledge, honouring and respecting it, is very much a part of what we should be doing.

... there's a lot of great minds, regardless of age, who are capable of doing good work. That opportunity should just be honoured and respected.

Norm Sheehan

Karen Seary: That really takes us to time out, so on behalf of everyone here I'd like to thank you, not only for your time, and your insights, but for your advice to us as enabling educators. I'm sure as a group, we will return to our own institutions a little more connected, as we always do, to those like-minded practitioners in other institutions. As we move forward, those connections are going to be crucial to our building a strong case for enabling education as we work towards articulating clearly what success means, not only in terms of hard outcomes, but those soft outcomes we all know to be exceptionally important. Thanks once again.

\section{NAEEA Conference}

\section{https://scu.edu.au/naeeaconference2017/}

